\title{
EL CAMBIO METODOLÓGICO EN EL ESPACIO EUROPEO DE EDUCACIÓN SUPERIOR Y EL PAPEL DE LAS TECNOLOGÍAS DE LA INFORMACIÓN Y LA COMUNICACIÓN
}

\author{
(THE METHODOLOGIC CHANGE IN THE EUROPEAN HIGHER EDUCATION AREA AND THE \\ ROLE PLAYED BY THE INFORMATION AND COMMUNICATION TECHNOLOGIES)
}

Juan De Pablos Pons

Universidad de Sevilla (España)

\section{RESUMEN}

Este artículo plantea algunos aspectos referidos a la renovación de las metodologías educativas que propone el Espacio Europeo de Educación Superior (EEES) y analiza el papel que puede jugar en esa renovación la utilización de las tecnologías de la información y la comunicación (TIC). Se hace una aproximación a algunas de las tecnologías a manejar por los docentes universitarios y su posible aportación a la labor docente, en base fundamentalmente a la digitalización y las redes informáticas, como es el caso de la Web 2.o. Igualmente se presentan algunos aspectos de una investigación realizada en la Universidad de Sevilla, en la que se muestra la percepción del profesorado sobre las posibles aportaciones de las TIC en el desarrollo de las propuestas vinculadas al Espacio Europeo de Educación Superior.

Palabras clave: tecnologías de la información y la comunicación, Espacio Europeo de Educación Superior, metodologías docentes, Web 2.0, aprendizaje virtual.

\begin{abstract}
This article raises some aspects referred to the renovation of the educational methodologies that proposes the European Higher Education Area (EHEA) and analyzes the role that can play in that renovation the use of the information and communication technologies (ICT). An approach to these technologies is made, so that it can be handled by the teachers and their possible contribution to the educational work, using the computer science digitalization and networks, as it is the case of Web 2.o. Also, some aspects of an investigation made in the University of Seville appear, where the teaching staff show their perceptions about contributions of the ICT in the development of the tie proposals to the European Higher Education Area.
\end{abstract}

Key words: information and communication technologies, European Higher Education Area, pedagogical methodologies, Web 2.0, e-learning. 


\section{EL SISTEMA UNIVERSITARIO ESPAÑOL Y EL PROCESO DE BOLONIA}

La conformación del Espacio Europeo de Educación Superior es hoy una realidad refrendada por un importante número de experiencias realizadas en las aulas universitarias y por diferentes directivas y normas legales ${ }^{1}$, dicha realidad representa una oportunidad de cambio para la Universidad española, de tal manera que su puesta en marcha ha hecho más visibles socialmente sus potencialidades pero también algunas de sus limitaciones actuales. En todo caso, el contexto de referencia del Sistema Universitario Español es el de la nueva sociedad del conocimiento, sobre la base de un modelo social, cultural y económico que se corresponde con el de los países avanzados, donde el componente tecnológico adquiere cada vez mayor relevancia. La creación de una Europa basada en el conocimiento es desde el Consejo Europeo de Lisboa, celebrado en el mes de marzo de 2000, uno de los objetivos fundamentales de la Unión Europea.

La Agenda de Lisboa insta a la participación y colaboración de numerosos sectores, entre los cuales las universidades desempeñan un papel especialmente importante, debido a su doble misión tradicional de investigación y enseñanza, a su papel cada vez más importante en el complejo proceso de innovación, así como a sus aportaciones a la creación de conocimiento y su transferibilidad al campo de la economía y a la cohesión social. Además, esta realidad se enmarca en un entorno cada vez más globalizado y en constante evolución, en el que es evidente un componente de competencia entre los centros universitarios tanto en oferta docente como en resultados de investigación, y garantizar así un nivel de excelencia duradero (Comisión de las Comunidades Europeas, 2003).

El Consejo de Educación de la Unión Europea ha declarado que Europa solamente podrá convertirse en una economía del conocimiento avanzada si la educación y la formación funcionan como motores de crecimiento económico, innovación, investigación, competitividad, empleo duradero, integración social y ciudadanía. Esta afirmación constituye todo un reto para el sistema educativo y en particular para las universidades, a las que se presupone una gran capacidad de renovación interna y de transformación de su entorno.

La incorporación del Sistema Universitario Español al denominado Proceso de Bolonia, iniciado en el año $1999^{2}$ ha quedado refrendada con la recientemente aprobada Ley Orgánica 4/2007 de Universidades por la que se modifica la Ley Orgánica 6/2001. En el título XIII de esta nueva norma legal se contempla el Espacio Europeo de Educación Superior (EEES) y la toma de medidas dirigidas a desarrollar 
plenamente la integración del sistema educativo universitario a dicho ámbito. Esta nueva situación en la que ha desembocado la universidad española supone, como cuestión clave, un cambio de la cultura organizativa de los centros universitarios; lo que representa modificar los modelos conceptuales, los valores y creencias que constituyen la identidad social del colectivo universitario (Martínez Mut y otros, 2005).

El Consejo de Coordinación Universitaria a través de su Comisión de Financiación ha hecho público (abril de 2007) un Informe sobre Financiación del Sistema Universitario Español en el que se analizan y destacan una serie de aspectos fundamentales sobre la situación de la Universidad española, señalando algunos de los principales problemas a resolver. La educación universitaria en España, tras la profunda transformación registrada en las dos últimas décadas, ha sufrido cambios muy significativos, que han afectado tanto a sus estructuras institucionales como a los modelos organizativos y sus vías de financiación. Su evolución se ha caracterizado por una acusada ampliación y diversificación de la oferta universitaria. Dicho Informe propone medidas económicas pero también estructurales y organizativas como alternativa para la serie de deficiencias constatadas.

\section{EL PAPEL DE LAS NUEVAS TECNOLOGÍAS EN EL MUNDO ACTUAL}

Planteado en clave filosófica, el siglo XX manejó en sus inicios una visión utópica del futuro y concluyó con una visión distópica del mismo, es decir como una utopía negativa donde la realidad transcurre en términos opuestos al ideal promulgado (Molinuevo, 2006); y todo ello ha sucedido en un contexto donde el desencanto sufrido por el desgaste de las ideologías ha propiciado nuevas visiones como el posmodernismo. Las distintas corrientes del movimiento posmoderno aparecieron en la segunda parte del siglo XX. Histórica, ideológica y metodológicamente diversas, comparten la idea-fuerza de que la renovación radical de las formas tradicionales en el arte, la cultura, el pensamiento y la vida social han fracasado en su intento de lograr la emancipación de la humanidad, de manera que un proyecto semejante es imposible o inalcanzable en las condiciones actuales. El posmodernismo defiende la hibridación de las ideas, la cultura popular, el descentramiento en definitiva, de la autoridad intelectual y científica.

Esta crisis de ideologías debe hacernos reflexionar sobre el final, tanto del excesivo optimismo de las utopías digitales extremas, en todas sus variantes, como de las más pesimistas distopías vinculadas hoy, en gran medida, a la biotecnología. 
Molinuevo señala esa crisis como causa de la actual transformación de todos los sistemas de transmisión de la información, por lo que propone como clave interpretativa un humanismo capaz de integrar las dos culturas: la de lo virtual y la de lo real, proclive a la mesura y consciente de que el ser humano es -lejos de todo determinismo y todo reduccionismo- un ser tecnológico. En función de las consideraciones anteriores, se trata de asumir la importancia de las tecnologías en el mundo actual, pero haciéndolo con un criterio equidistante entre lo utópico y lo reaccionario (Molinuevo, 2004).

En ese proceso de cambio de visión asumieron importantes niveles de protagonismo las tecnologías y posteriormente las llamadas nuevas tecnologías como elementos de ruptura y cambio. De hecho, hay autores que analizan las tecnologías como un factor transformador (Shallis, 1984; Sancho, 2006). Si algo caracteriza al desarrollo tecnológico es que remite permanentemente hacia el futuro. Sin embargo, en los comienzos del siglo XXI las nuevas tecnologías ya no se contemplan como un factor revolucionario, sino que vienen contribuyendo a una serie de cambios vinculados a la evolución de una serie de realidades. De hecho, ha dejado de utilizarse el término revolución, en relación con las tecnologías y el sentido actual más aceptado ha derivado hacia una expresión posiblemente más precisa: la metáfora. Se trata, por tanto, de expresar la incorporación de cambios producidos en diferentes órdenes de la vida a través del impacto de las tecnologías. Esto supone considerarlas como componentes inicialmente ajenos, que han pasado a formar parte significativa de algunas de nuestras realidades y actividades cotidianas. El término impacto es otra de las metáforas tomadas del mundo físico para explicar la presencia significativa de los nuevos medios en cada vez más ámbitos sociales, económicos, culturales o de ocio (Molinuevo, 2006, p. 97).

En todo caso, la vieja dicotomía entre reaccionarios temerosos del cambio y defensores de la utopía tecnológica sigue presente, sin embargo resulta útil para disponer de una visión más objetiva, basada en una visión analítica y crítica. La tecnología condiciona hoy, en buena medida, el actual horizonte social, cultural, político e incluso antropológico, como ya anticiparon los futuristas con el entusiasmo de quien cree que progreso social y progreso tecnológico van de la mano, y lo lamentaron los filósofos de la existencia, proclives a denunciar la deshumanización y el desarraigo causados por la universalización de la técnica y la reducción de todo conocimiento a mera información. Este análisis dicotomizado también se ha aplicado al campo de la educación en términos de tecnofilia y tecnofobia, como formas de ocultación de la problemática de la educación escolar (Sancho, 1998). 
En el ámbito de la educación superior, y en coherencia con la reflexión anterior, por mor de las tecnologías la universidad tradicional no ha sufrido una revolución, no han desaparecido sus estructuras tradicionales, pero sí que se han producido cambios significativos, apoyados por las tecnologías, además de manera constante en los últimos años. Así ha sido en cuanto a sus objetivos, sus modelos de gestión y en sus prioridades docentes e investigadoras. La estandarización ha hecho posible que el uso de la tecnología sea más generalizado y menos complejo (Pittinsky, 2006).

Neil Postman ha planteado una distinción relevante entre una tecnología y un medio. Así, una tecnología se convierte en un medio cuando obtiene un lugar en un contexto social determinado. De tal manera que, una tecnología es simplemente una herramienta, una máquina, mientras que un medio es una creación social y cultural (Postman, 2006, p. 145). Este planteamiento implica que la utilización de una tecnología por parte de una determinada cultura en particular no es necesariamente la única forma en que puede ser utilizada. En consecuencia, es posible utilizar una tecnología de modo que sus consecuencias sociales, económicas o políticas sean muy diferentes de una cultura a otra. Por lo tanto, esa "transformación" de una tecnología en un medio útil y aplicable, es un proceso que tiene que llevarse a cabo tanto en un plano social e institucional, como en un plano personal, buscando y encontrando esa "utilidad real" que la tecnología puede aportar como valor añadido.

\section{EL CAMBIO EN LAS METODOLOGÍAS DOCENTES UNIVERSITARIAS VINCULADO AL USO DE LAS TIC}

Existen bastantes evidencias respecto a que el Sistema Universitario Español ha recibido la puesta en marcha del Espacio Europeo de Educación Superior, en buena medida, como un horizonte de cambio en las metodologías docentes dirigido a mejorar la calidad pedagógica, más que como un problema de adaptación a una nueva unidad de cuenta, el sistema europeo de transferencia y acumulación de créditos (ECTS) ${ }^{3}$. A ello han contribuido de forma determinante los mensajes de los responsables gubernamentales. Con este cambio metodológico se pretende reducir las clases magistrales, basadas en dinámicas fundamentalmente expositivas, y dar más peso a las actividades prácticas, las tutorías y al trabajo individualizado con el estudiante. La ampliación del abanico metodológico pretende manejar opciones que den respuesta a diferentes y nuevas finalidades, como el dominio de competencias. Así, métodos como el estudio de casos, el aprendizaje basado en problemas, el aprendizaje orientado a proyectos, el aprendizaje cooperativo, la resolución de problemas o el contrato de aprendizaje son alternativas pedagógicas a manejar por los docentes universitarios (De Miguel, 2006). 
En esta línea abunda el documento elaborado por la Comisión para la Renovación de las Metodologías Educativas en la Universidad ${ }^{4}$. En dicho informe se plantea el proceso de construcción del Espacio Europeo de Educación Superior (EEES) como "la oportunidad perfecta para impulsar una reforma que no debe quedarse en una mera reconversión de la estructura y contenidos de los estudios, sino que debe alcanzar al meollo de la actividad universitaria, que radica en la interacción profesores-estudiantes para la generación del aprendizaje" (2006, p. 7). En todo caso, debe señalarse que la metodología docente universitaria en los modelos europeos actuales se caracteriza por la heterogeneidad, considerándose como referentes a seguir, las enseñanzas que fomentan la actividad y un mayor grado de implicación de los estudiantes en su formación, a partir de modelos de formación más flexibles y abiertos. En este sentido, el citado informe señala la conveniencia de crear en las universidades españolas servicios que asuman la gestión de planes específicos para la renovación de las metodologías universitarias (PERME).

En este contexto de cambio metodológico, el papel de las tecnologías de la información y la comunicación aparece señalado como un factor relevante y facilitador de los planteamientos alternativos que docentes y estudiantes deben asumir. Así, diferentes estudios realizados en el ámbito universitario español (Alba, 2004; Barros, 2004; Michavila, 2004; o el ya citado informe del Consejo de Coordinación Universitaria sobre la Renovación de las Metodologías Educativas en la Universidad, 2006) señalan a las tecnologías de la información y la comunicación como factores influyentes de apoyo al cambio metodológico.

Ya en aportaciones anteriores (De Pablos, 2005; De Pablos y Villarciervos, 2005) hemos analizado el papel que las nuevas tecnologías pueden tener en la innovación de la docencia universitaria dentro del marco del EEES. Desde un punto de vista realista, la incorporación de las tecnologías de la información y la comunicación (TIC) a la universidad española se está llevando a cabo de una manera progresiva. Su uso sistematizado en las aulas y el desarrollo de modalidades como la tutorización virtual o la creación de grupos de trabajo en red son prácticas hoy habituales en la universidad española. En cuanto a la "reconversión" de las tareas del profesorado, desarrollando nuevas funciones, se concreta en opciones que progresivamente se van incorporando, tales como la elaboración de materiales para ser utilizados en red, siendo esta la opción más elemental. Otros desarrollos cada vez más habituales son la edición de cursos virtuales apoyados en el uso de plataformas formativas, y la virtualización completa de asignaturas (mediante la utilización de materiales integrados, como documentos hipermedia, vídeos digitalizados, programas autoinstruccionales, portafolios digitales, etc.). 
En otro nivel de propuestas, la creación de redes universitarias basadas en la cooperación permiten la potenciación de aspectos como la multidisciplinaridad, la movilidad e intercambio de profesores y estudiantes, la internacionalización de los curricula, la difusión del conocimiento y la oferta de servicios. Su ampliación a otros sectores públicos y productivos, pueden facilitar la suma de esfuerzos para lograr objetivos formativos y de investigación más ambiciosos y enmarcados en iniciativas con más proyección.

Las potencialidades educativas de las redes informáticas obligan a replantear en profundidad tanto la dimensión individual como colectiva de los procesos de enseñanza-aprendizaje, los ritmos o tiempos de aprendizaje, las nuevas formas de estructurar la información para la construcción de conocimiento, así como las tareas y competencias docentes y discentes. De ahí que la formación pedagógica del profesorado en TIC se convierta en uno de los factores claves para su utilización en los sistemas de formación. Ello implica la construcción de una nueva pedagogía basada en estos nuevos recursos, que posibilite e integre lo local con lo global y que haga compatible la formación en centros educativos con la constitución de redes temáticas especializadas que construyan y reconstruyan conocimientos y saberes disciplinares. Este potencial ha de canalizarse a través de la creación de nuevos modelos y de formas de gestión pedagógica que permitan la explotación de las posibilidades interactivas del espacio virtual (De Pablos, 2005).

Las características de las TIC y los procesos para integrarlas en la educación, han sido relacionados con la idea de que su presencia debe ser interpretada como sinónimo de calidad educativa. La capacidad potencial de estas tecnologías para generar nuevos entornos de aprendizaje, adaptados a las características y niveles de las personas en formación aporta su carácter como mediadores en los procesos de aprendizaje e incluso sus posibilidades para modificar la interactividad generada. De tal manera que, en el campo educativo, la calidad vinculada al uso de las tecnologías en realidad se relaciona en buena medida con la calidad de la interactividad, como factor clave en los procesos de enseñanza-aprendizaje. Esta interactividad no es valorable en sí misma, sino a través de los entornos y "espacios de trabajo" que proponen las tecnologías. Y esos entornos, a su vez, son consecuencia de los modelos de aprendizaje en que se sustentan.

En la práctica estos planteamientos se hacen visibles a través del análisis de los procesos de interacción que se ponen en juego. Las interacciones entre profesores y estudiantes; la integración de los materiales de estudio; la contribución de las TIC para facilitar determinados formatos de interacción, etc. Por lo tanto, hablamos de 
diferentes modalidades deinteractividad: individual, grupal,jerárquica, horizontal, de gestión, evaluativa, etc. La identificación de las diferentes modalidades de interacción en contextos y entornos reales, es la manera más adecuada para conocer la calidad de una oferta formativa, que puede tomar una forma concreta con el desarrollo de dimensiones e indicadores, plasmados en instrumentos evaluadores. La evaluación de la calidad en la educación superior es un asunto complejo y que también requiere de replanteamientos y búsquedas de fórmulas nuevas. Hasta ahora, el tratamiento de la calidad se ha manejado mayoritariamente en parámetros cuantitativos; esto es, la cantidad de dinero por estudiante, el número de alumnos por profesor, etc. Pero es necesario sobreponer una serie de datos cualitativos, que aporten información sobre aspectos como la diversificación del currículum, la internacionalización y la movilidad de los estudiantes o la introducción de sistemas obligatorios de evaluación de las instituciones, que permitan una lectura más matizada de la realidad de las aulas universitarias y ayuden a generalizar la "cultura de la calidad" (Michavila, 2005).

\section{La web 2.o y las universidades}

Desde el año 2004 se ha introducido un término en el campo de las TIC que identifica un conjunto de iniciativas o tendencias en los usos de Internet; se trata de la expresión Web 2.o. En ese año 2004 la editorial O'Reilly Media tomó la iniciativa de organizar una conferencia que denominó Web 2.o. El término fue acuñado por Dale Dougherty para sugerir que la web estaba en esos momentos en un proceso expansivo con reglas y conceptos que evolucionaban. En consecuencia, la denominación Web 2.o se utiliza, para identificar una serie de conceptos, tecnologías y fundamentalmente una nueva actitud hacia esas tecnologías y sus aplicaciones.

El hecho de que la web se está convirtiendo en la plataforma sobre la que se ejecutan nuestras aplicaciones, cada vez de manera más independiente del sistema operativo de nuestro ordenador, representa un cambio muy significativo y trascendente. Es necesario destacar el concepto de software social, que se refiere al uso de la comunicación mediada por ordenador para la formación de comunidades: una aplicación basada en la web se pone a disposición de una multitud de usuarios que aportan e intercambian información.

Así, Web 2.o trata de diferenciarse de una presunta Web 1.o que correspondería a una concepción de la tecnología web y sus aplicaciones, anterior a 1999. Las características de la Web 1.0 se vinculan a herramientas como el buscador Altavista, el correo Hotmail, el gestor de páginas gratuitas GeoCities, la enciclopedia Encarta, el 
gestor de imágenes Ofoto o el navegador Netscape, cuyo lugar toman progresivamente herramientas equivalentes «2.0», como Google, GMail, Blogger, Wikipedia, Flickr o Firefox, respectivamente. A pesar de ello, prácticamente todas las tecnologías que caracterizan esta nueva «versión» estaban ya presentes con notable anterioridad al 2004 y, en muchos casos, incluso en 1999. (Anderson, 2007).

Dentro de este planteamiento nos encontramos con la idea de Universidad 2.0 como espacio de intercambio y de conocimiento académico en red, donde destaca el potencial de los blogs en las dos áreas básicas de la enseñanza superior: docencia e investigación. Algunas características propias del formato, como son su facilidad y la interactividad con los usuarios, hacen de esta herramienta un medio idóneo para el trabajo con modelos de enseñanza en red -edublogs-, así como para su adaptación a proyectos de divulgación científica -blogs académicos-. Estas dos aplicaciones los convierten en un instrumento de gran interés para avanzar en la experimentación con las líneas recomendadas tanto por el Espacio Europeo de Educación Superior como la apuesta por el Open Access que ha recogido la Declaración de Berlín ${ }^{5}$.

Cada vez son más las instituciones, investigadores, profesores y estudiantes que comienzan a relacionarse y compartir conocimiento a través de las tecnologías identificadas como Web 2.o. La Universidad de Harvard fue pionera en 2003 al ofrecer un servicio de blogs a su comunidad educativa para así propiciar la experimentación con las posibilidades comunicativas del medio. En España algunas instituciones académicas han integrado también este modelo. El proyecto H2O impulsa un grupo de comunidades interconectadas basadas en la libre creación e intercambio de ideas. H2o proporciona "playlists" (listas compartidas para lecturas, blogs, podcasts y otros contenidos) que pueden ser catalogadas y suscritas mediante RSS. Las denominadas "playlists" son elaboradas por cualquier usuario y son publicadas a través de la fórmula de licencia libre Creative Commons.

En la State University de Nueva York, se desarrolla el Geneseo Collaborative Writing Project que facilita wikis para los estudiantes con el objeto de que trabajen conjuntamente en la interpretación de textos, artículos y trabajos, compartan ideas y mejoren sus habilidades para investigar y comunicarse colectivamente. Esta opción también ha sido utilizada en una herramienta desarrollada en la Universidad de Oxford (Phoebe) para apoyar a los profesores en fomentar un tipo de aprendizaje que explore nuevas aproximaciones didácticas y el uso de nuevas herramientas. Con la denominación Design for learning ${ }^{6}$ un consorcio de universidades inglesas han implementado una iniciativa que busca la innovación pedagógica basada en el uso de las TIC. Los responsables de este proyecto señalan que "se proporciona una 
perspectiva diferente y alternativa a las prácticas tradicionales en la planificación de los cursos y las clases. Descansa no sólo en el énfasis del papel de la tecnología en el aprendizaje, sino también en la efectividad: creando diseños para experiencias que sean motivadoras, divertidas y productivas para los estudiantes y profesores".

Evidentemente estas iniciativas abren numerosas cuestiones que van desde la falta de cultura tecnológica de una parte del profesorado, que se visibiliza al tener que afrontar una nueva terminología o aprender el uso de nuevas herramientas informáticas, hasta la carencia de actitudes en el estudiantado para utilizar este "software social" en la dimensión del aprendizaje, más allá de los usos en los que triunfa el Internet actualmente.

Manuel Area (2004) plantea en clave de reto la integración de las tecnologías de comunicación digitales, fundamentalmente Internet, en los procesos formativos utilizados en la enseñanza superior. Y por tanto, hablamos de cambiar las formas de comunicación entre los docentes y el alumnado, y los procesos de enseñanza y aprendizaje. Esta cuestión es nuclear porque encamina al profesorado hacia la reformulación de las formas de trabajo y la innovación de la enseñanza.

Lasinstituciones deenseñanza superior están siendo requeridas para dar respuesta a demandas de formación más flexibles y adaptadas, a ciclos formativos más cortos y a la necesidad de incorporar sistemas pedagógicos más activos y participativos, según el marco establecido por el Proceso de Bolonia. Esta tarea debe hacerse de manera reflexiva y coherente, no por un reflejo condicionado, consecuencia de una demanda externa a corto plazo, regida por el mercado. Las universidades deben ofrecer respuestas a los problemas reales de manera fundamentada y no únicamente en clave económica.

En síntesis, la utilización de la tecnología con fines educativos y formativos supone abordar cuestiones fundamentales sobre las metas y los propósitos generales de un centro universitario. A su vez, los propios objetivos educativos han de tener en cuenta las nuevas oportunidades que estas tecnologías ofrecen (Bates, 2001).

\section{LA ADAPTACIÓN DEL PROFESORADO AL EEES Y SU PERCEPCIÓN DEL PAPEL DE LAS TIC}

Las diferentes universidades españolas han iniciado los procesos de incorporación al Espacio Europeo de Educación Superior mediante diferentes iniciativas vinculadas a la información y formación del profesorado, estudiantes 
y personal de administración y servicios. Estos pasos se han pretendido dar a partir de un conocimiento realista de la situación. Es el caso de la Universidad de Sevilla, de manera que su equipo rectoral ha encargado diferentes estudios, tanto de carácter descriptivo (De Pablos, 2006a) como prescriptivo (De Pablos, 2006b). En relación a este último, titulado Estudio prospectivo sobre las potencialidades de la universidad de Sevilla para facilitar su adaptación al Espacio Europeo de Educación Superior ${ }^{7}$, se presentan a continuación algunos datos y análisis referidos específicamente al profesorado.

La finalidad fundamental de esta investigación ha sido la de realizar un análisis estratégico de la situación de la Universidad de Sevilla para la toma de decisiones sobre su adaptación al Espacio Europeo de Educación Superior. Para su desarrollo este estudio ha contemplado una perspectiva integrada que incorpora una visión interna, destinada a conocer la percepción de sus miembros sobre las ventajas y dificultades de la situación actual de la Universidad de Sevilla, y valorar los cambios que debe realizar en su oferta de titulaciones; y otra visión externa, destinada a conocer las demandas sociales, tanto en perfiles de formación como en titulaciones.

Este análisis se ha realizado a partir de las informaciones provenientes de diferentes agentes internos: profesores, alumnos, decanos y directores de departamento. También de los agentes externos consultados: egresados, empresarios, profesores de bachillerato y administración pública.

El estudio se ha orientado a conseguir cinco objetivos generales, para el caso de los agentes internos arriba mencionados. A saber:

- Evaluar las ventajas y dificultades de la situación actual de la Universidad de Sevilla respecto a su adaptación al Espacio Europeo de Educación Superior.

- Significar los beneficios esperados por la incorporación de la Universidad de Sevilla al Espacio Europeo de Educación Superior.

- Detectar los inconvenientes de la Universidad de Sevilla que dificultan su adaptación al Espacio Europeo de Educación Superior.

- Mostrar las adaptaciones necesarias para ajustar la oferta de titulaciones a las demandas sociales del entorno de la Universidad de Sevilla y al Espacio Europeo de Educación Superior.

- Identificar el potencial de la Universidad de Sevilla en el que apoyar la mejora de su oferta formativa e investigadora. 
La selección de las muestras correspondientes a los diferentes colectivos consultados en el estudio de los agentes internos, se ha realizado mediante un muestreo estratificado controlado. Se han considerado las 26 Facultades de la Universidad de Sevilla como los distintos estratos que conforman el universo universitario y se han seleccionado de cada uno de estos estratos y al azar, un número de personas proporcional al número que de ese estrato se encuentra en la población. Se ha elaborado un cuestionario específico para cada uno de los colectivos consultados. En el caso del colectivo docente, la muestra final utilizada ha sido de 139 profesores, pertenecientes a todos los niveles académicos y las grandes áreas de conocimiento.

Sobre la base de los objetivos citados, se han realizado un conjunto de análisis sobre la información obtenida de los que a continuación, vamos a presentar algunos resultados referidos a la percepción y demanda del profesorado. La información ha sido recogida durante el curso 2005-2006 mediante un cuestionario específico cumplimentado vía Internet, y reforzado mediante la realización de entrevistas telefónicas. La validación del cuestionario en cuanto a su estructura y contenido se ha apoyado en el juicio previo de expertos y la realización de un estudio piloto que ha permitido depurar los ítems utilizados.

Los aspectos contemplados en los análisis mostrados a continuación se refieren a los conocimientos, adaptación y demandas formativas que declaran los profesores de la Universidad de Sevilla consultados. En este marco se ha interrogado sobre el papel a jugar por las tecnologías de la información y la comunicación en diferentes supuestos.

\section{Adaptación de los docentes al Espacio Europeo de Educación Superior}

El reto que plantea el proceso de Convergencia Europea supone para el profesorado universitario emprender una serie de actuaciones que implica asumir una dinámica de adaptación. En este sentido, en la tabla siguiente mostramos los resultados obtenidos para una serie de indicadores de diagnóstico del proceso de adaptación, en función de las principales pautas que señala el EEES.

Una lectura conjunta de la tabla siguiente permite ilustrar el estado actual de la cuestión en cuanto al proceso y actuaciones seguidas por el profesorado para la adaptación al crédito europeo. Así, el 71,9\% del profesorado declara que integra las TIC en la formación universitaria, el 68,3 \% se muestra disponible para la movilidad a otros países europeos, el 60,4 \% del profesorado encuestado considera 
que plantea la formación de su materia en términos de competencias y el 61,9 \% ha formado parte de equipos de trabajo o redes docentes para la elaboración de proyectos de investigación, innovación, guías docentes, etc.

\begin{tabular}{|c|c|c|c|}
\hline \multicolumn{2}{|l|}{ ADAPTACIÓN DOCENTE AL EEES } & $\begin{array}{l}\text { Frecuencia } \\
\text { (f) }\end{array}$ & $\begin{array}{c}\text { Porcentaje } \\
(\%)\end{array}$ \\
\hline \multirow{3}{*}{ He recibido cursos sobre el Crédito Europeo (ECTS) } & No & 81 & 58,3 \\
\hline & Sí & 58 & 41,7 \\
\hline & Total & 139 & 100 \\
\hline \multirow{3}{*}{ Planteo la formación de mi materia en términos de competencias } & No & 55 & 39,6 \\
\hline & Sí & 84 & 60,4 \\
\hline & Total & 139 & 100 \\
\hline \multirow{3}{*}{$\begin{array}{l}\text { Aplico sistemas de evaluación para detectar niveles de logro en } \\
\text { competencias }\end{array}$} & No & 56 & 40,3 \\
\hline & Sí & 83 & 59,7 \\
\hline & Total & 139 & 100 \\
\hline \multirow{3}{*}{$\begin{array}{l}\text { Utilizo sistemas de trabajo flexibles y dinámicos con los estudiantes } \\
\text { adaptados a las metodologías ECTS }\end{array}$} & No & 64 & 46 \\
\hline & Sí & 75 & 54 \\
\hline & Total & 139 & 100 \\
\hline \multirow{3}{*}{ Integro las TIC en la formación universitaria } & No & 39 & 28,1 \\
\hline & Sí & 130 & 71,9 \\
\hline & Total & 139 & 100 \\
\hline \multirow{3}{*}{ Estoy disponible para la movilidad a otros países europeos } & No & 44 & 31,7 \\
\hline & Sí & 95 & 68,3 \\
\hline & Total & 139 & 100 \\
\hline \multirow{3}{*}{ Leo y hablo varios idiomas } & No & 30 & 21,6 \\
\hline & Sí & 109 & 78,4 \\
\hline & Total & 139 & 100 \\
\hline \multirow{3}{*}{$\begin{array}{l}\text { He utilizado servicios de asesoramiento para la adaptación al crédito } \\
\text { europeo }\end{array}$} & No & 95 & 68,3 \\
\hline & Sí & 44 & 31,7 \\
\hline & Total & 139 & 100 \\
\hline \multirow{3}{*}{$\begin{array}{l}\text { He formado parte de equipos de trabajo o redes docentes para la elaboración } \\
\text { de proyectos de investigación, innovación, guías docentes, etc. }\end{array}$} & No & 53 & 38,1 \\
\hline & Sí & 86 & 61,9 \\
\hline & Total & 139 & 100 \\
\hline
\end{tabular}

Tabla 1. Actuaciones de adaptación docente al EEES

El gráfico siguiente presenta cómo el 54\% reconoce utilizar sistemas de trabajo flexibles y dinámicos con los estudiantes adaptados a las metodologías ECTS, frente al 46\% que afirma no hacerlo. Y un 59,7\% reconoce aplicar sistemas de evaluación para detectar niveles de logro en competencias. 
El Cambio Metodológico en el Espacio Europeo de Educación Superior...

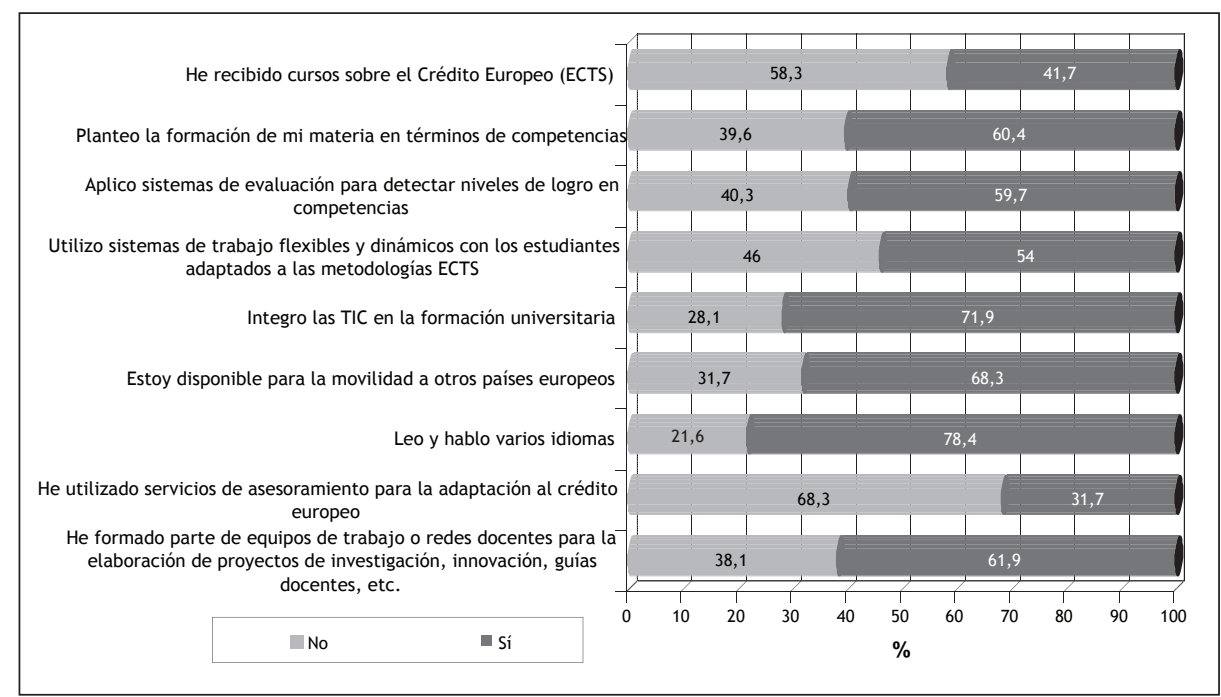

Gráfico 1. Actuaciones de adaptación docente al EEES

La siguiente tabla de resultados nos permite obtener una imagen proyectiva de la relevancia que el profesorado otorga a las facetas antes planteadas:

\begin{tabular}{|l|c|c|c|c|}
\hline \multicolumn{1}{|c|}{ RELEVANCIA DE LAS CUESTIONES PLANTEADAS } & N & Media & $\begin{array}{c}\text { Desviación } \\
\text { típ. }\end{array}$ & $\begin{array}{c}\text { Error típ. de } \\
\text { la media }\end{array}$ \\
\hline $\begin{array}{l}\text { Considera un requisito relevante recibir cursos sobre el Crédito Europeo } \\
\text { (ECTS) }\end{array}$ & 135 & 3,6000 & 1,03808 &, 08934 \\
\hline $\begin{array}{l}\text { Considera un requisito relevante plantear la formación de mi materia en } \\
\text { términos de competencias }\end{array}$ & 120 & 3,4333 & 1,01031 &, 09223 \\
\hline $\begin{array}{l}\text { Considera un requisito relevante aplicar sistemas de evaluación para } \\
\text { detectar niveles de logro en competencias }\end{array}$ & 122 & 3,4836 &, 94680 &, 08572 \\
\hline $\begin{array}{l}\text { Considera un requisito relevante utilizar sistemas de trabajo flexibles y } \\
\text { dinámicos con los estudiantes adaptados a las metodologías ECTS }\end{array}$ & 125 & 3,5200 &, 92979 &, 08316 \\
\hline Considera un requisito relevante integrar las TIC en la formación universitaria & 134 & 3,4403 & 1,00008 &, 08639 \\
\hline $\begin{array}{l}\text { Considera un requisito relevante estar disponible para la movilidad a } \\
\text { otros países europeos }\end{array}$ & 132 & 3,1591 & 1,17109 &, 10193 \\
\hline Considera un requisito relevante leer y hablar varios idiomas & 135 & 3,7481 &, 99790 &, 08589 \\
\hline $\begin{array}{l}\text { Considera un requisito relevante utilizar servicios de asesoramiento para } \\
\text { la adaptación al crédito europeo }\end{array}$ & 123 & 3,2114 &, 94307 &, 08503 \\
\hline $\begin{array}{l}\text { Considera un requisito relevante formar parte de equipos de trabajo } \\
\text { o redes docentes para la elaboración de proyectos de investigación, } \\
\text { innovación, guías docentes, etc. }\end{array}$ & 139 & 3,2086 & 1,39083 &, 11797 \\
\hline
\end{tabular}

Tabla 2. Estadísticos descriptivos. Grado de relevancia de los requisitos del crédito ECTS 
El gráfico siguiente presenta de forma ordenada los aspectos considerados por el profesorado de mayor a menor relevancia (en un rango de 1 a 4):

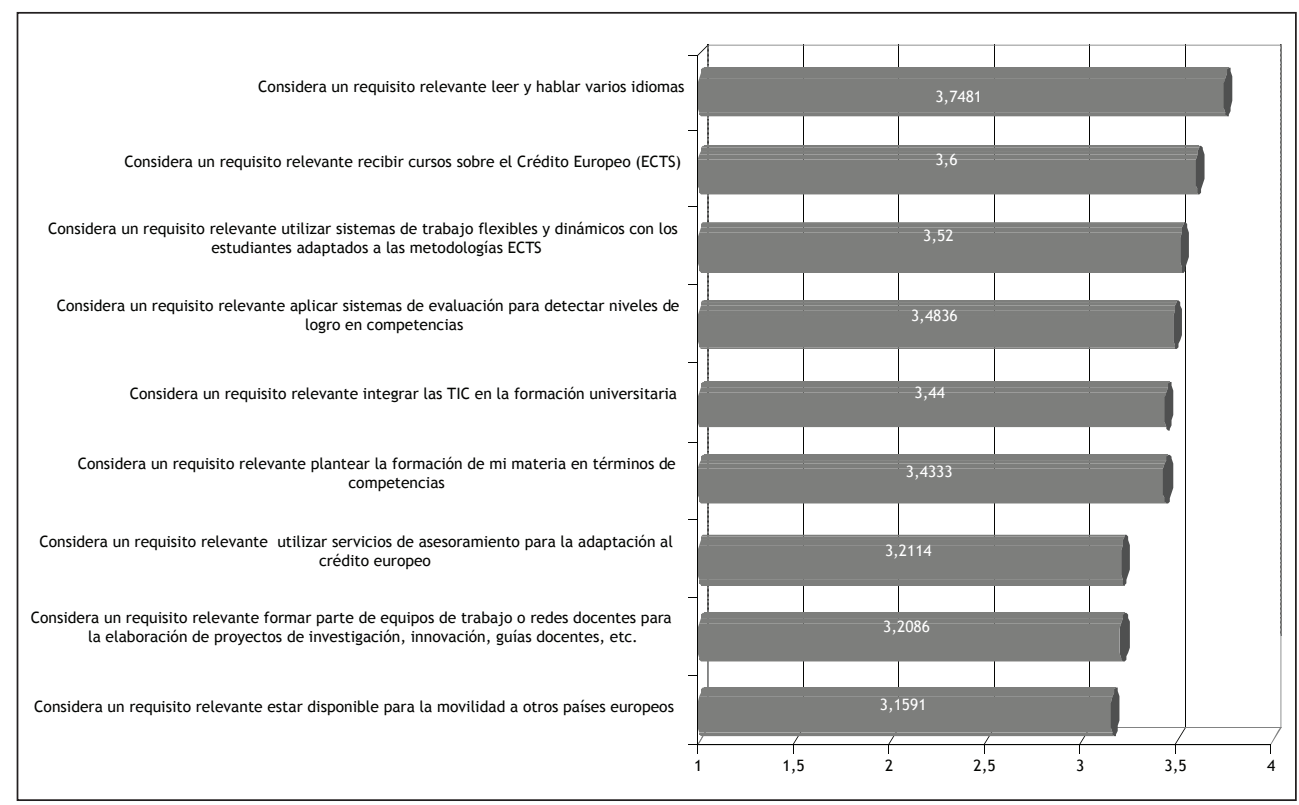

Gráfico 2. Grado de relevancia de los requisitos ECTS

Para detectar si los aspectos considerados como relevantes por el profesorado difieren del valor promedio (valor 3), hemos aplicado la prueba t para una muestra. La tabla siguiente muestra los resultados obtenidos del contraste sobre el valor promedio de los aspectos considerados. 
El Cambio Metodológico en el Espacio Europeo de Educación Superior...

\begin{tabular}{|c|c|c|c|c|c|c|}
\hline \multirow{3}{*}{$\begin{array}{l}\text { RELEVANCIA DE LAS CUESTIONES } \\
\text { PLANTEADAS }\end{array}$} & \multicolumn{6}{|c|}{ Valor de prueba $=3$} \\
\hline & \multirow[t]{2}{*}{$\mathrm{t}$} & \multirow[t]{2}{*}{ gl } & \multirow[t]{2}{*}{$\begin{array}{l}\text { Sig. } \\
\text { (bilateral) }\end{array}$} & \multirow[t]{2}{*}{$\begin{array}{l}\text { Diferencia } \\
\text { de medias }\end{array}$} & \multicolumn{2}{|c|}{$\begin{array}{l}95 \% \text { Intervalo de } \\
\text { confianza para la } \\
\text { diferencia }\end{array}$} \\
\hline & & & & & Inferior & Superior \\
\hline Recibir cursos sobre el Crédito Europeo (ECTS) & 6,716 & 134 &, 000 &, 6000 & ,4233 & ,7767 \\
\hline $\begin{array}{l}\text { Plantear la formación de mi materia en términos de } \\
\text { competencias }\end{array}$ & 4,698 & 119 &, 000 & ,4333 & ,2507 &, 6160 \\
\hline $\begin{array}{l}\text { Aplicar sistemas de evaluación para detectar niveles } \\
\text { de logro en competencias }\end{array}$ & 5,642 & 121 &, 000 & ,4836 & ,3139 &, 6533 \\
\hline $\begin{array}{l}\text { Utilizar sistemas de trabajo flexibles y dinámicos con } \\
\text { los estudiantes adaptados a las metodologías ECTS }\end{array}$ & 6,253 & 124 &, 000 &, 5200 & ,3554 & ,6846 \\
\hline Integrar las TIC en la formación universitaria & 5,096 & 133 &, 000 & ,4403 & ,2694 & 6112 \\
\hline $\begin{array}{l}\text { Estar disponible para la movilidad a otros países } \\
\text { europeos }\end{array}$ & 1,561 & 131 &, 121 & ,1591 &,- 0426 & ,3607 \\
\hline Leer y hablar varios idiomas & 8,711 & 134 &, 000 &, 7481 & ,5783 & ,9180 \\
\hline $\begin{array}{l}\text { Utilizar servicios de asesoramiento para la adaptación } \\
\text { al crédito europeo }\end{array}$ & 2,486 & 122 &, 014 & 2114 & ,0430 & ,3797 \\
\hline $\begin{array}{l}\text { Formar parte de equipos de trabajo o redes docentes } \\
\text { para la elaboración de proyectos de investigación, } \\
\text { innovación, guías docentes, etc. }\end{array}$ & 1,769 & 138 & ,079 & 2086 &,- 0246 & ,4419 \\
\hline
\end{tabular}

Tabla 3. Grado de relevancia de los requisitos del crédito ECTS.

Prueba para una muestra

Los resultados expuestos en la tabla precedente ponen de manifiesto la existencia de diferencias significativas entre las valoraciones dadas por los sujetos al grado de relevancia de los requisitos del crédito ECTS y el valor promedio teórico. Sólo dos de los aspectos no muestran diferencias significativas con el valor promedio: estar disponible para la movilidad a otros países $(\mathrm{p}=0,121)$ y formar parte de equipos de trabajo o redes docentes para la elaboración de proyectos $(\mathrm{p}=0,079)$. La valoración que hace el profesorado de la relevancia del resto de cuestiones planteadas se muestra significativamente superior al promedio. Por ello, podemos concluir que el profesorado considera como relevantes la mayor parte de los requisitos planteados para la incorporación al EEES, quedando incluido por tanto la integración de las TIC en la formación universitaria. 
Esta información puede ser simplificada merced a un número menor de factores que den cuenta de una proporción razonable de variabilidad explicada. Hemos aplicado, en este sentido, la técnica de análisis factorial, con el procedimiento de extracción de componentes principales. Al objeto de obtener más de un factor, hemos forzado al sistema a cambiar el criterio (convencional) de autovalores mayor o igual a la unidad por autovalores mayores o iguales a 0.9. Al final, el porcentaje de variabilidad explicada ha sido del 65,68\%

Varianza total explicada

\begin{tabular}{|c|c|c|c|c|c|c|c|c|c|}
\hline \multirow{2}{*}{ 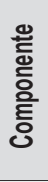 } & \multicolumn{3}{|c|}{ Autovalores iniciales } & \multicolumn{3}{|c|}{$\begin{array}{l}\text { Sumas de las saturaciones al } \\
\text { cuadrado de la extracción }\end{array}$} & \multicolumn{3}{|c|}{$\begin{array}{l}\text { Suma de las saturaciones } \\
\text { al cuadrado de la rotación }\end{array}$} \\
\hline & Total & $\begin{array}{l}\% \text { de la } \\
\text { varianza }\end{array}$ & $\begin{array}{c}\% \\
\text { acumulado }\end{array}$ & Total & $\begin{array}{l}\% \text { de la } \\
\text { varianza }\end{array}$ & $\begin{array}{c}\% \\
\text { acumulado }\end{array}$ & Total & $\begin{array}{l}\% \text { de la } \\
\text { varianza }\end{array}$ & $\begin{array}{c}\% \\
\text { acumulado }\end{array}$ \\
\hline 1 & 4,004 & 44,494 & 44,494 & 4,004 & 44,494 & 44,494 & 2,612 & 29,019 & 29,019 \\
\hline 2 & ,991 & 11,016 & 55,510 & ,991 & 11,016 & 55,510 & 1,747 & 19,414 & 48,433 \\
\hline 3 & ,916 & 10,173 & 65,683 & ,916 & 10,173 & 65,683 & 1,552 & 17,250 & 65,683 \\
\hline 4 & ,897 & 9,972 & 75,655 & & & & & & \\
\hline 5 & ,599 & 6,659 & 82,314 & & & & & & \\
\hline 6 & ,483 & 5,365 & 87,679 & & & & & & \\
\hline 7 & ,464 & 5,152 & 92,832 & & & & & & \\
\hline 8 & ,347 & 3,856 & 96,688 & & & & & & \\
\hline 9 & 298, & 3,312 & 100,000 & & & & & & \\
\hline
\end{tabular}

Método de extracción: Análisis de Componentes principales

El primer factor, y el más importante en términos de variabilidad explicada, está constituido por elementos que hacen referencia a cuestiones metodológicas específicas del nuevo enfoque educativo aportado por el proceso de adaptación al EEES (trabajo por competencias, integración de las TIC en la dinámica curricular, evaluación continua, etc.). Un segundo factor donde se pone el acento en el aspecto interdisciplinario (equipos de trabajo y asesoramiento). $\mathrm{Y}$ un tercer factor donde se destaca la relevancia de la proyección europea (idiomas y movilidad). 
Matriz de componentes rotados

\begin{tabular}{|c|c|c|c|}
\hline & \multicolumn{3}{|c|}{ Componentes } \\
\hline & 1 & 2 & 3 \\
\hline $\begin{array}{l}\text { Considera un requisito relevante aplicar sistemas de evaluación para detectar niveles } \\
\text { de logro en competencias. }\end{array}$ & .825 & -.015 & .287 \\
\hline $\begin{array}{l}\text { Considera un requisito relevante plantear la formación de mi materia en términos de } \\
\text { competencias. }\end{array}$ & .766 & .177 & 192 \\
\hline $\begin{array}{l}\text { Considerar un requisito relevante utilizar sitemas de trabajo flexibles y dinámicos con } \\
\text { los estudiantes adaptados a las metodologías ECTS. }\end{array}$ & .714 & .264 & .207 \\
\hline Considera un requisito relevante integrar las TIC en la formación universitaria. & .670 & .326 & .066 \\
\hline $\begin{array}{l}\text { Considerar un requisito relevante formar parte de equipos de trabajo o redes docentes } \\
\text { para la elaboración de proyectos de investigación, innovación, guías docentes, etc. }\end{array}$ & .119 & .810 & .097 \\
\hline $\begin{array}{l}\text { Considera un requisito relevante utilizar servicios de asesoramiento para la adaptación } \\
\text { al crédito europeo. }\end{array}$ & .197 & .735 & .273 \\
\hline Considera un requisito relevante recibir cursos sobre el Crédito Europeo (ECTs). & .427 & .514 & .076 \\
\hline Considera un requisito relevante leer y hablar varios idiomas. & .165 & .110 & .882 \\
\hline $\begin{array}{l}\text { Considera un requisito relevante estar disponible para la movilidad a otros países } \\
\text { europeos. }\end{array}$ & .288 & .258 & .719 \\
\hline
\end{tabular}

Método de extracción: Análisis de componentes principales. Métodos de rotación: Normalización Varimax con Kaiser.

a. La rotación ha convergido en 5 iteraciones

\section{Necesidades formativas del profesorado en relación al EEES}

En cuanto a las necesidades formativas declaradas por el profesorado de la Universidad de Sevilla podemos observar, a partir de los datos expuestos en la tabla siguiente, que los ítems más valorados son la formación en nuevas metodologías (formas de enseñar) adaptadas a las directrices del crédito europeo con un $64 \%$ de profesores que así lo consideran, y la formación en la elaboración de programas de materias según el modelo ECTS (con un 63,3\% del profesorado). El 59,7\% del profesorado de la Universidad de Sevilla demanda formación para aplicar las TIC en la docencia, como tercera preferencia. 


\begin{tabular}{|c|c|c|c|}
\hline \multicolumn{2}{|l|}{ ASPECTOS EN LOS QUE EL PROFESORADO NECESITA FORMACIÓN } & $\begin{array}{c}\text { Frecuencia } \\
\text { (f) }\end{array}$ & $\begin{array}{c}\text { Porcentaje } \\
(\%)\end{array}$ \\
\hline \multirow{3}{*}{$\begin{array}{l}\text { Formación en nuevas metodologías (formas de enseñar) adaptadas a las } \\
\text { directrices del crédito europeo }\end{array}$} & No & 50 & 36 \\
\hline & Sí & 89 & 64 \\
\hline & Total & 139 & 100 \\
\hline \multirow{3}{*}{$\begin{array}{l}\text { Formación en aplicar las TIC (Tecnologías de la Información y la Comunicación) } \\
\text { a la docencia (elaboración de páginas web, teletutorías, etc.) }\end{array}$} & No & 56 & 40,3 \\
\hline & Sí & 83 & 59,7 \\
\hline & Total & 139 & 100 \\
\hline \multirow{3}{*}{ Formación en el conocimiento de otros idiomas } & No & 68 & 48,9 \\
\hline & Sí & 71 & 51,1 \\
\hline & Total & 139 & 100 \\
\hline \multirow{3}{*}{ Formación en programas de movilidad } & No & 77 & 55,4 \\
\hline & Sí & 62 & 44,6 \\
\hline & Total & 139 & 100 \\
\hline \multirow{3}{*}{$\begin{array}{l}\text { Formación en la elaboración de programas de materias según el modelo } \\
\text { ECTS }\end{array}$} & No & 51 & 36,7 \\
\hline & Sí & 88 & 63,3 \\
\hline & Total & 139 & 100 \\
\hline
\end{tabular}

Tabla 4. Necesidades formativas del profesorado

El gráfico siguiente permite visualizar las necesidades de formación valoradas por el profesorado en base a la tabla precedente.

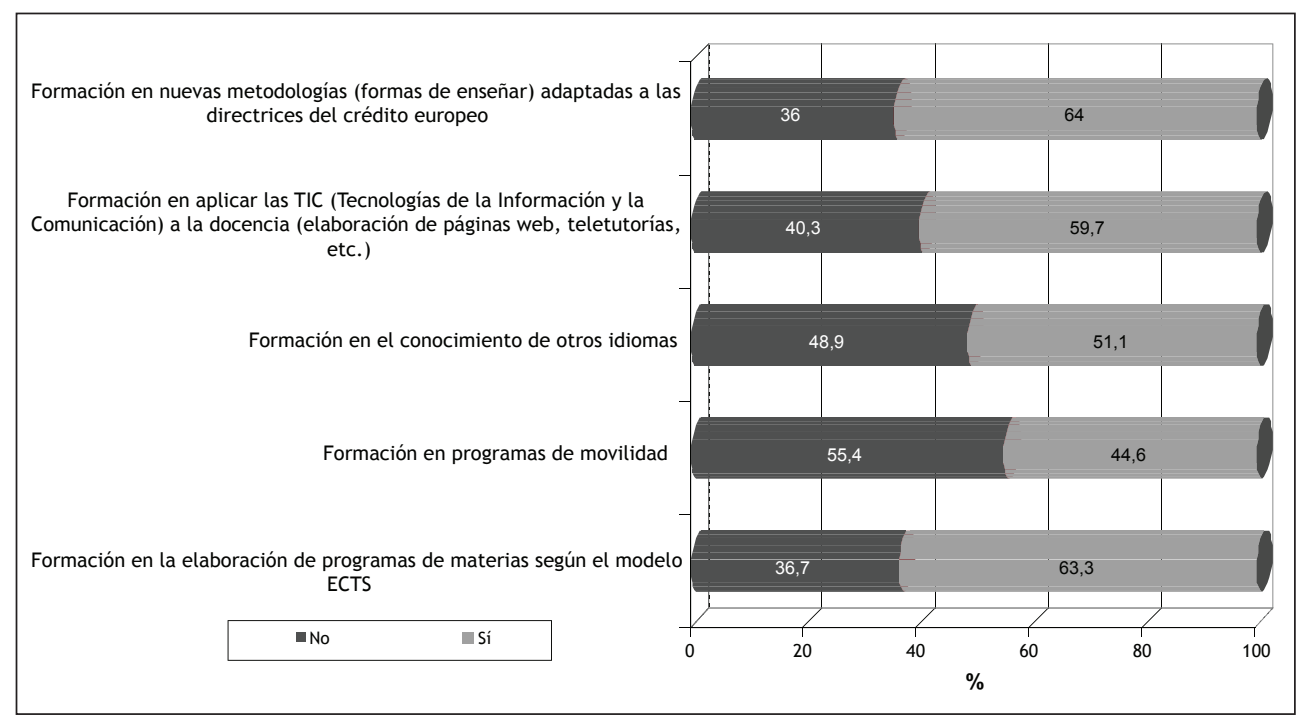

Gráfico 3. Necesidades formativas del profesorado 


\section{Beneficios esperados por el profesorado como consecuencia de su incorporación al EEES}

Los resultados en torno a los beneficios esperados de la incorporación al EEES en cuanto a la oferta formativa de la Universidad de Sevilla se pueden contemplar en la siguiente tabla:

\begin{tabular}{|c|c|c|c|c|}
\hline $\begin{array}{l}\text { BENEFICIOS ESPERADOS DE LA INCORPORACIÓN AL EEES } \\
\text { EN CUANTO A LA OFERTA FORMATIVA DE LA UNIVERSIDAD } \\
\text { DE SEVILLA }\end{array}$ & $\mathbf{N}$ & Media & $\begin{array}{l}\text { Desviación } \\
\text { tip. }\end{array}$ & $\begin{array}{l}\text { Error típ. de } \\
\text { la media }\end{array}$ \\
\hline $\begin{array}{l}\text { Beneficio de Mayores oportunidades profesionales para los } \\
\text { profesores }\end{array}$ & 121 & 2,6694 & 1,09078 & ,09916 \\
\hline $\begin{array}{l}\text { Beneficio de Integración de las Tecnologías en el Sistema } \\
\text { Universitario }\end{array}$ & 126 & 3,1746 & ,99663 & 08879 \\
\hline $\begin{array}{l}\text { Beneficio de Formación adaptada a las demandas del mercado } \\
\text { laboral }\end{array}$ & 128 & 2,9375 & 1,03292 & 09130 \\
\hline Beneficio de Movilidad de recursos humanos (profesores y alumnos) & 123 & 3,3496 & 1,14508 & 10325 \\
\hline $\begin{array}{l}\text { Beneficio de Diversificación de la oferta formativa (masters, } \\
\text { postgrados, etc.) }\end{array}$ & 129 & 3,1705 & 1,05419 & 09282 \\
\hline $\begin{array}{l}\text { Beneficio de Responsabilidad del estudiante ante su propio } \\
\text { aprendizaje }\end{array}$ & 130 & 3,2846 & 1,31912 & ,11569 \\
\hline Beneficio de Estructuras organizativas más flexibles & 120 & 3,0583 & 1,05556 & 09636 \\
\hline Beneficio de Dinamismo en la gestión institucional & 95 & 2,8632 & 1,08775 & ,11160 \\
\hline $\begin{array}{l}\text { Beneficio de Ampliación de las oportunidades laborales de los } \\
\text { egresados }\end{array}$ & 112 & 3,1875 & 1,18193 & ,11168 \\
\hline
\end{tabular}

Tabla 5. Estadísticos descriptivos. Beneficios esperados de la incorporación al EEES en cuanto a la oferta formativa de la Universidad de Sevilla.

A partir de los estadísticos mostrados arriba, podemos observar que el profesorado considera como "algo beneficiosas" todas las sentencias planteadas, ya que los valores de las medias están próximos al valor 3 de forma generalizada (para un rango entre 1 y 4). Entre los beneficios esperados de la incorporación al EEES el profesorado destaca la movilidad de recursos humanos (profesores y alumnos) con una media de 3,3496 y la responsabilidad del estudiante ante su propio aprendizaje con una media de 3,2846. A estos beneficios esperados les siguen la ampliación de las oportunidades laborales de los egresados (media 3,1875) y la integración de las Tecnologías en el Sistema Universitario (media 3,1746). Para esta última, el nivel de dispersión de las respuestas del profesorado es el menor contemplado (desviación típica 0,99663). 
El Cambio Metodológico en el Espacio Europeo de Educación Superior...

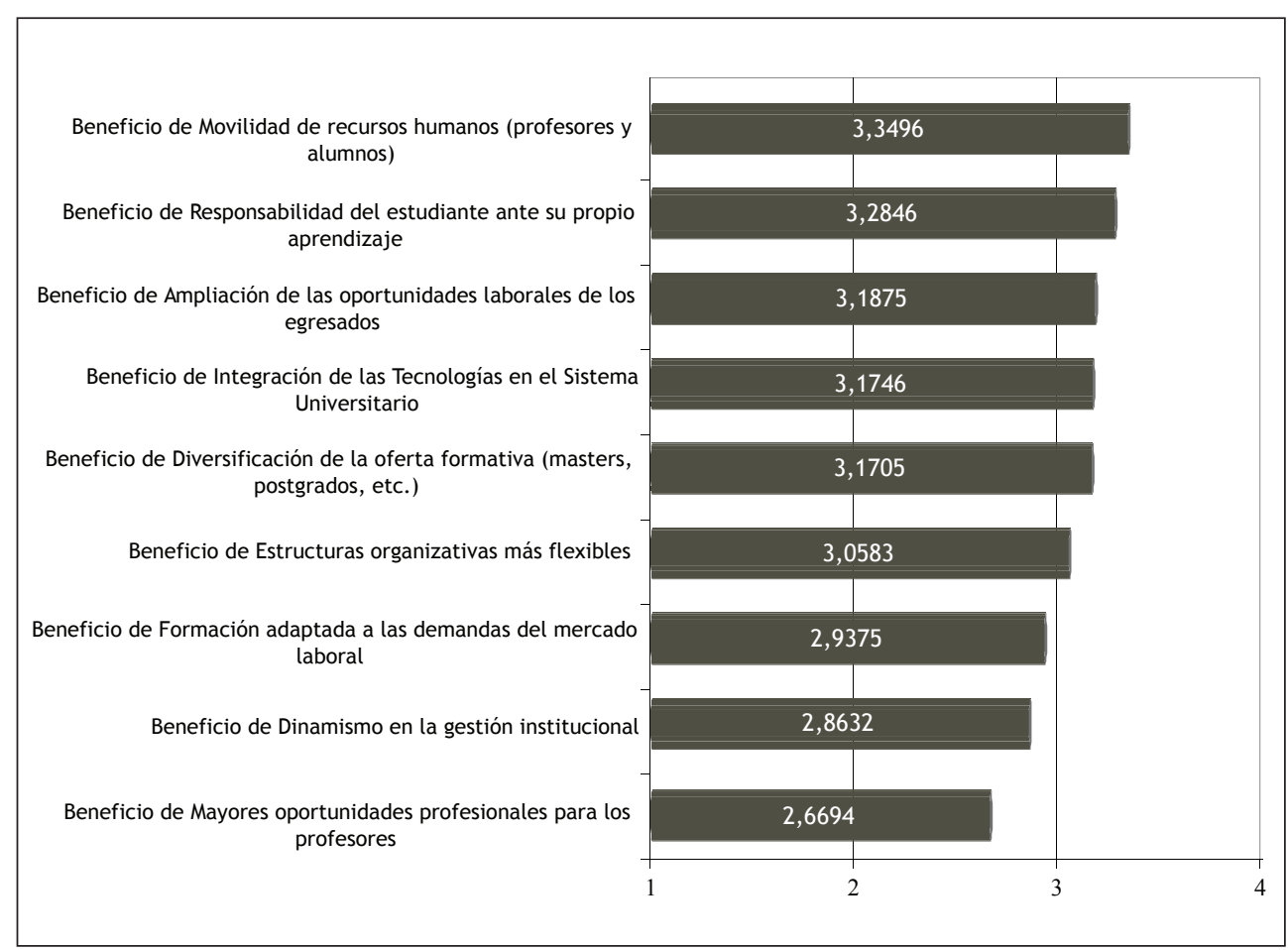

Gráfico 4. Beneficios esperados de la incorporación al EEES

Tal y como podemos apreciar en el gráfico precedente, La integración de las TIC en el Sistema Universitario ocupa el cuarto lugar entre nueve opciones referidas a beneficios esperados. En este sentido, podemos afirmar que, el profesorado, considera que, los cambios derivados de la incorporación de la Universidad de Sevilla al EEES aportarán algún beneficio en términos generales. No obstante, para detectar si los beneficios considerados por el profesorado difieren del valor promedio (valor 3, algo beneficiosos), hemos aplicado la prueba t para una muestra. La tabla siguiente muestra los resultados obtenidos del contraste sobre el valor promedio de los beneficios considerados. 
El Cambio Metodológico en el Espacio Europeo de Educación Superior...

\begin{tabular}{|c|c|c|c|c|c|c|}
\hline \multirow{3}{*}{$\begin{array}{l}\text { BENEFICIOS ESPERADOS DE LA INCORPORACIÓN } \\
\text { AL EEES EN CUANTO A LA OFERTA FORMATIVA DE } \\
\text { LA UNIVERSIDAD DE SEVILLA }\end{array}$} & \multicolumn{6}{|c|}{ Valor de prueba $=3$} \\
\hline & \multirow[t]{2}{*}{$\mathrm{t}$} & \multirow[t]{2}{*}{ gl } & \multirow[t]{2}{*}{$\begin{array}{l}\text { Sig. } \\
\text { (bilateral) }\end{array}$} & \multirow[t]{2}{*}{$\begin{array}{l}\text { Diferencia } \\
\text { de medias }\end{array}$} & \multicolumn{2}{|c|}{$\begin{array}{c}95 \% \text { Intervalo de } \\
\text { confianza para la } \\
\text { diferencia }\end{array}$} \\
\hline & & & & & Inferior & Superior \\
\hline $\begin{array}{l}\text { Beneficio de Mayores oportunidades profesionales para } \\
\text { los profesores }\end{array}$ & $-3,334$ & 120 &, 001 &,- 3306 &,- 5269 &,- 1342 \\
\hline $\begin{array}{l}\text { Beneficio de Integración de las Tecnologías en el Sistema } \\
\text { Universitario }\end{array}$ & 1,967 & 125 &, 051 & ,1746 &,- 0011 & ,3503 \\
\hline $\begin{array}{l}\text { Beneficio de Formación adaptada a las demandas del } \\
\text { mercado laboral }\end{array}$ &,- 685 & 127 & ,495 &,- 0625 &,- 2432 & ,1182 \\
\hline $\begin{array}{l}\text { Beneficio de Movilidad de recursos humanos (profesores } \\
\text { y alumnos) }\end{array}$ & 3,386 & 122 &, 001 & ,3496 & ,1452 &, 5540 \\
\hline $\begin{array}{l}\text { Beneficio de Diversificación de la oferta formativa } \\
\text { (masters, postgrados, etc.) }\end{array}$ & 1,837 & 128 &, 068 &, 1705 &,- 0131 & ,3542 \\
\hline $\begin{array}{l}\text { Beneficio de Responsabilidad del estudiante ante su } \\
\text { propio aprendizaje }\end{array}$ & 2,460 & 129 & ,015 & ,2846 & 0557 &, 5135 \\
\hline Beneficio de Estructuras organizativas más flexibles & ,605 & 119 &, 546 & ,0583 &,- 1325 & ,2491 \\
\hline Beneficio de Dinamismo en la gestión institucional & $-1,226$ & 94 & ,223 &,- 1368 &,- 3584 & ,0847 \\
\hline $\begin{array}{l}\text { Beneficio de Ampliación de las oportunidades laborales } \\
\text { de los egresados }\end{array}$ & 1,679 & 111 &, 096 & ,1875 &,- 0338 & ,4088 \\
\hline
\end{tabular}

Tabla 5. Beneficios esperados de la incorporación al EEES en cuanto a la oferta formativa de la Universidad de Sevilla. Prueba para una muestra.

Los resultados expuestos en la tabla precedente parecen poner de manifiesto que existen diferencias significativas entre tres beneficios contemplados en el estudio y el valor promedio. Así, el beneficio de mayores oportunidades profesionales para los profesores $(\mathrm{p}=0,001)$, el de la movilidad de los recursos humanos $(\mathrm{p}=0,001)$ $\mathrm{y}$ el de la responsabilidad del estudiante ante su propio aprendizaje $(\mathrm{p}=0,015)$ se muestran de manera significativa diferentes al valor promedio 3 con un nivel de confianza del $95 \%$. La diferencia de las medias nos ilustra si esas diferencias son a la alza o la baja. Y por tanto, el beneficio de la movilidad de los recursos humanos (con diferencia de medias 0,3496) y el beneficio de responsabilidad del estudiante ante su propio aprendizaje (con diferencia de medias 0,2846) se muestran como diferencialmente más beneficiosos con respecto a los otros. La integración de las TIC en el Sistema Universitario $(\mathrm{p}=0,1746)$ se sitúa en un rango intermedio en cuanto a beneficios esperados. 
De forma que, podemos concluir que el profesorado deposita especialmente su confianza en que la incorporación del EEES supondrá como cambios más beneficiosos la movilidad de los recursos humanos y la responsabilidad del estudiante ante su propio aprendizaje.

\section{Inconvenientes percibidos por el profesorado como consecuencia de su incorporación al EEES}

Los resultados obtenidos en relación a los inconvenientes percibidos por parte del profesorado que dificultan la adaptación al EEES se exponen en la tabla siguiente:

\begin{tabular}{|c|c|c|c|c|}
\hline $\begin{array}{l}\text { INCONVENIENTES PERCIBIDOS QUE DIFICULTAN LA } \\
\text { ADAPTACIÓN AL EEES }\end{array}$ & $\mathbf{N}$ & Media & $\begin{array}{l}\text { Desviación } \\
\text { típ. }\end{array}$ & $\begin{array}{l}\text { Error típ. de } \\
\text { la media }\end{array}$ \\
\hline Inconveniente de más trabajo personal para el profesorado & 137 & 3,0292 & 1,23635 &, 10563 \\
\hline $\begin{array}{l}\text { Inconveniente de cambios en los hábitos de estudio y de } \\
\text { trabajo de los estudiantes }\end{array}$ & 136 & 3,4044 & 1,17618 &, 10086 \\
\hline $\begin{array}{l}\text { Inconveniente de movilidad de recursos humanos } \\
\text { (profesores y alumnos) }\end{array}$ & 122 & 2,2705 & 1,13572 & ,10282 \\
\hline $\begin{array}{l}\text { Inconveniente de adaptación de los programas formativos } \\
\text { actuales al crédito europeo }\end{array}$ & 135 & 2,8370 & 1,10769 & 09533 \\
\hline $\begin{array}{l}\text { Inconveniente de manejar en mayor grado los recursos } \\
\text { tecnológicos }\end{array}$ & 134 & 1,6866 & ,76990 &, 06651 \\
\hline Inconveniente de la gestión Institucional actual & 103 & 3,3301 & 1,20772 & ,11900 \\
\hline Inconveniente de la estructura organizativa actual & 110 & 3,3545 & 1,11361 &, 10618 \\
\hline $\begin{array}{l}\text { Inconveniente de mayor implicación del estudiante en su } \\
\text { aprendizaje }\end{array}$ & 139 & 3,0000 & 1,35668 &, 11507 \\
\hline $\begin{array}{l}\text { Inconveniente de la orientación actual de la formación } \\
\text { universitaria hacia un modelo académico }\end{array}$ & 139 & 2,6331 & 1,63363 & 13856, \\
\hline
\end{tabular}

Tabla 6. Estadísticos descriptivos. Inconvenientes percibidos para la adaptación al EEES.

A partir de los estadísticos mostrados en la tabla precedente, podemos observar en diferencias de grado, lo que, el profesorado percibe como inconvenientes para la adaptación al EEES, en función de las diversas sentencias planteadas. Los valores de las medias nos aproximan a observar diferentes grados en estas consideraciones. En primer lugar, los inconvenientes que reúnen un mayor valor de la media son los cambios en los hábitos de estudio y de trabajo de los estudiantes (3,4044), la estructura organizativa actual $(3,3545)$ y la gestión institucional actual $(3,3301)$. 
El Cambio Metodológico en el Espacio Europeo de Educación Superior...

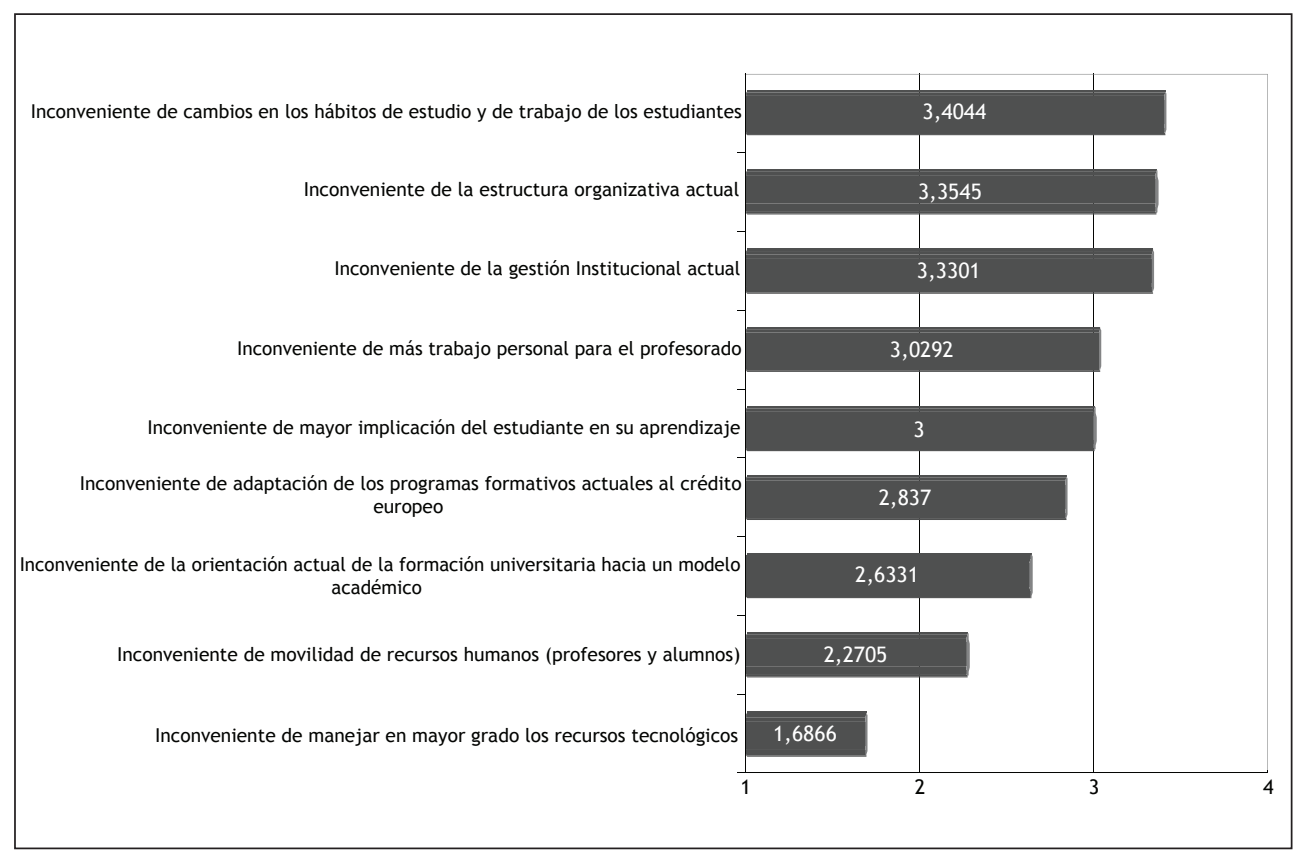

Gráfico 5. Inconvenientes percibidos para la adaptación al EEES

Como podemos apreciar en el gráfico el inconveniente percibido como menor por el profesorado es el de manejar en mayor grado los recursos tecnológicos (media 1,6866). Esta sentencia presenta una desviación típica de 0,76990 lo que indica cierta dispersión en las valoraciones emitidas por parte del profesorado con respecto a la media. No obstante, para detectar si los inconvenientes percibidos por el profesorado difieren del valor promedio (valor 3, equivalente a algo inconveniente), hemos aplicado la prueba $t$ para una muestra. La tabla siguiente muestra los resultados obtenidos del contraste sobre el valor promedio de los inconvenientes considerados. 
El Cambio Metodológico en el Espacio Europeo de Educación Superior...

\begin{tabular}{|c|c|c|c|c|c|c|}
\hline \multirow{3}{*}{$\begin{array}{l}\text { INCONVENIENTES PERCIBIDOS QUE DIFICULTAN } \\
\text { LA ADAPTACIÓN AL EEES }\end{array}$} & \multicolumn{6}{|c|}{ Valor de prueba $=3$} \\
\hline & \multirow[t]{2}{*}{$\mathrm{t}$} & \multirow[t]{2}{*}{ gl } & \multirow[t]{2}{*}{$\begin{array}{c}\text { Sig. } \\
\text { (bilateral) }\end{array}$} & \multirow[t]{2}{*}{$\begin{array}{l}\text { Diferencia } \\
\text { de medias }\end{array}$} & \multicolumn{2}{|c|}{$\begin{array}{c}95 \% \text { Intervalo de } \\
\text { confianza para la } \\
\text { diferencia }\end{array}$} \\
\hline & & & & & Inferior & Superior \\
\hline $\begin{array}{l}\text { Inconveniente de más trabajo personal para el } \\
\text { profesorado }\end{array}$ & ,276 & 136 & ,783 &, 0292 &,- 1797 & ,2381 \\
\hline $\begin{array}{l}\text { Inconveniente de cambios en los hábitos de estudio y de } \\
\text { trabajo de los estudiantes }\end{array}$ & 4,010 & 135 &, 000 & ,4044 & ,2049 & 6039 \\
\hline $\begin{array}{l}\text { Inconveniente de movilidad de recursos humanos } \\
\text { (profesores y alumnos) }\end{array}$ & $-7,095$ & 121 &, 000 &,- 7295 &,- 9331 &,- 5259 \\
\hline $\begin{array}{l}\text { Inconveniente de adaptación de los programas } \\
\text { formativos actuales al crédito europeo }\end{array}$ & $-1,709$ & 134 & 090 &,- 1630 &,- 3515 & 0256 \\
\hline $\begin{array}{l}\text { Inconveniente de manejar en mayor grado los recursos } \\
\text { tecnológicos }\end{array}$ & $-19,748$ & 133 &, 000 & $-1,3134$ & $-1,4450$ & $-1,1819$ \\
\hline Inconveniente de la gestión Institucional actual & 2,774 & 102 &, 007 & ,3301 &, 0941 &, 5661 \\
\hline Inconveniente de la estructura organizativa actual & 3,339 & 109 & ,001 &, 3545 & ,1441 & ,5650 \\
\hline $\begin{array}{l}\text { Inconveniente de mayor implicación del estudiante en } \\
\text { su aprendizaje }\end{array}$ & ,000 & 138 & 1,000 & ,0000 &,- 2275 & 2275 \\
\hline $\begin{array}{l}\text { Inconveniente de la orientación actual de la formación } \\
\text { universitaria hacia un modelo académico }\end{array}$ & $-2,648$ & 138 & ,009 &,- 3669 &,- 6409 &,- 0929 \\
\hline
\end{tabular}

Tabla 7. Inconvenientes percibidos para la adaptación al EEES. Prueba para una muestra

Los resultados expuestos en la tabla precedente parecen poner de manifiesto que existen diferencias significativas entre seis de los inconvenientes contemplados en el estudio y el valor promedio. Así, el inconveniente de los cambios en los hábitos de estudio y de trabajo de los estudiantes $(\mathrm{p}=\mathrm{0}, \mathrm{000})$, el de movilidad de recursos humanos (profesores y alumnos) ( $\mathrm{p}=\mathrm{0}, 0 \mathrm{0o})$, el de manejar en mayor grado los recursos tecnológicos ( $\mathrm{p}=\mathrm{0}, \mathrm{000})$, el de la gestión Institucional actual ( $\mathrm{p}=\mathrm{0}, \mathrm{001})$, el de la estructura organizativa actual ( $\mathrm{p}=0,007)$ y el de la orientación actual de la formación universitaria hacia un modelo académico $(\mathrm{p}=0,009)$ se muestran significativamente diferentes al valor promedio 3 con un nivel de confianza del 95\%. La diferencia de las medias nos ilustra si esas diferencias son al alza o a la baja. Y por tanto, los inconvenientes de manejar en mayor grado los recursos tecnológicos (distancia entre medias -1,3134), el de movilidad de recursos humanos -profesores y alumnos- (-0,7295) y el de orientación actual de la formación universitaria hacia un modelo académico $(-0,3669)$ se perciben diferencialmente como poco inconvenientes. 


\section{A MODO DE CONCLUSIÓN}

La incorporación sistemática y en clave docente de las tecnologías de la información y la comunicación a una institución tan compleja como la universidad, representa un conjunto de transformaciones relevantes, muchas de ellas ya en proceso de aplicación en el caso español. El dominio de las competencias referidas al uso de las TIC es un referente de partida, pero los cambios para ser incorporados son de índole muy variada.

Las decisiones sobre el grado de presencialidad y virtualidad en las diferentes modalidades de enseñanza, deberán tomarse en función de las posibilidades reales de los escenarios que estas dos opciones básicas exigen, y en los que las tecnologías y los recursos humanos desempeñan roles distintos (Bates, 2001). La integración de las TIC en procesos formativos, según el concepto vinculado al crédito europeo ECTS, puede permitir una mayor flexibilización, mediante el desarrollo de diferentes opciones. Tales como facilitar a los estudiantes el control de su propio proceso de aprendizaje; favorecer el dominio de competencias específicas en el uso de las TIC, especialmente cuando dicho dominio forma parte de los objetivos de la propia actividad formativa; potenciar la interacción entre el profesorado y los estudiantes, al disponer de más canales para su comunicación; y en definitiva, favorecer una mejor adaptación de docentes y estudiantes al plan de trabajo formativo.

El profesorado universitario debe sensibilizarse respecto a los cambios de roles vinculados a la presencia de las tecnologías de la información y la comunicación en el marco docente, valorando que pueden liberarlo en cierta medida de la tarea de transmitir información y conocimientos, para convertirlo en dinamizador y referente del proceso de aprendizaje. Esta situación exige un análisis en profundidad sobre cómo diseñar y planificar la formación pedagógica del profesorado.

Las TIC y especialmente Internet ponen al alcance de los docentes y estudiantes el acceso inmediato a bases de datos, bibliotecas digitales y materiales multimedia que deben estar integrados en el plan de trabajo ofertado. Hace diez años se escribían los primeros posts. Hoy, los propios blogs son objeto de investigación en forma de tesis doctorales y analizados en congresos académicos. Los ciclos son cada vez más cortos y es posible que no tengamos que esperar otra década para celebrar una evolución tan significativa en los flujos de comunicación.

Las nuevas tecnologías de la comunicación representan, bajo estas formulaciones, la opción de un apoyo consistente para propiciar un cambio 
fundamental en las formas y procedimientos de interacción en las aulas universitarias. Estos cambios parecen encajar bien con los objetivos y planteamientos formulados en el marco del Espacio Europeo de Educación Superior. Los procesos en la interactividad comunicativa que propician las nuevas tecnologías de la información y la comunicación parecen invitar a una "revolución de la cultura docente". La autoridad de los profesores ya no deriva de detentar el monopolio del conocimiento sino de la capacidad para enseñar a elaborar el conocimiento a partir de la información y de enseñar a aprender. Estamos hablando, por tanto, de una revisión de las estrategias docentes utilizadas hasta ahora. La lógica de los procesos de la gestión del conocimiento queda así replanteada.

Los datos aportados en relación a las percepciones y demandas realizados por los profesores de la Universidad de Sevilla indican, como ejemplo concreto pero significativo, que el profesorado universitario asume las tecnologías de la información y la comunicación y las integra en sus propuestas formativas, lo que no impide una demanda formativa en estos aspectos, ya que una de las principales características de las TIC es su constante evolución y avance en propuestas que pueden favorecer la equidad, la eficiencia, y en definitiva, la calidad de la educación.

La realización de los cambios aquí analizados y valorados, en clave pedagógica, deben sostener en buena medida, la consecución de los principios de calidad, movilidad, diversidad y competitividad que el Espacio Europeo de Educación Superior pretende para sus instituciones, sus profesionales y, fundamentalmente, sus estudiantes.

\section{NOTAS}

1 Los Reales Decretos 55/2005 y 56/2005, ambos de 21 de enero (modificados por el Real Decreto 1509/2005, de 16 de diciembre) establecen la estructura de las enseñanzas universitarias y regulan los estudios universitarios oficiales de grado y posgrado. Asimismo, el Real Decreto 1044/2003 de 1 de agosto regula la expedición del suplemento europeo al título; y el Real Decreto 1125/2003 de 5 de septiembre regula el establecimiento del sistema europeo de créditos ECTS.

2 Acuerdo institucional firmado por 29 países europeos, a partir de los principios establecidos en la Declaración de París-La Sorbona el año anterior elaborada por los ministros de educación de Francia, Reino Unido, Alemania e Italia. 
3 El Sistema europeo de transferencia y acumulación de créditos (ECTS) es un sistema centrado en el estudiante, que se basa en la carga de trabajo del estudiante, necesaria para la consecución de los objetivos de un programa. Estos objetivos se especifican preferiblemente en términos de los resultados del aprendizaje y de las competencias que se han de adquirir.

4 Propuestas para la Renovación de las Metodologías Educativas en la Universidad. Consejo de Coordinación Universitaria, Ministerio de Educación y Ciencia, 2006.

5 La declaración de Berlín fue suscrita por los ministros de educación superior en el año 2003: http://www.mec.es/universidades/eees/files/o30919Berlin_ Communique.pdf

6 http://www.jisc.ac.uk/whatwedo/programmes/elearning_pedagogy/elp_ designlearn.aspx

7 Este estudio ha sido financiado por la Universidad de Sevilla en el marco de su Plan Propio para la Convergencia Europea, a iniciativa del Vicerrectorado de Ordenación Académica (Secretariado de Convergencia Europea).

\section{REFERENCIAS BIBLIOGRÁFICAS}

Alba, C. (Dir.) (2004). Viabilidad de las propuestas metodológicas derivadas de la aplicación del crédito europeo por parte del profesorado de las universidades españolas, vinculadas a la utilización de las TIC en la docencia y la investigación. Madrid: Dirección General de Universidades, MEC.

Anderson, P. (2007). What is Web 2.0? Ideas, technologies and implications for education. JISC. Technology and Standards Watch. [en línea] Disponible en: http://www.jisc.ac.uk/media/ documents/techwatch/tsw0701b.pdf [consulta 2006, 7 de octubre]

Area, M. (2004). Los medios y las tecnologías en la educación. Madrid: Editorial Pirámide.

Barros, S. (Dir.) (2004). Las TIC en el sistema universitario español. Madrid: CRUE.

Bates, A. (2001). Cómo gestionar el cambio tecnológico. Estrategias para los responsables de centros universitarios. Barcelona: Gedisa/EDIUOC, 2001.

Comisión de las Comunidades Europeas (2003). El papel de las Universidades en la Europa del Conocimiento. Bruselas. (Comunicación 58/2003).

Consejo de Coordinación Universitaria (2006). Propuestas para la renovación de las metodologías educativas en la Universidad. Madrid: Secretaría General Técnica del MEC. [en línea] Disponible en: http://www.mec.es/ educa/ccuniv/html/metodologias/ docu/PROPUESTA RENOVACION. pdf [consulta 2006, 7 de octubre]

Consejo de Coordinación Universitaria (2007). Financiación del Sistema Universitario Español. Madrid: Comisión de Financiación, MEC. [en línea] Disponible en: http://sites. upc.edu/ www-eees/contingut/ arxius/Informe $\% 20$ Financiacion $\%$ 20-\%20CCU\%20-20-04-2007.pdf [consulta 2006, 7 de octubre] 
De Pablos, J. (2005). El Espacio Europeo de Educación Superior y las Tecnologías de la Información y la Comunicación, en: Colás, P.; De Pablos, J.: La Universidad en la Unión Europea. El Espacio Europeo de Educación Superior y su impacto en la docencia. Málaga: Ediciones Aljibe, 57-75.

De Pablos, J.; Villarciervos, P. (2005). El Espacio Europeo de Educación Superior y las tecnologías de la información y la comunicación. Percepciones y demandas del profesorado. Revista de Educación, 337, 99-124.

De Pablos, J. (Coord.) (2006a). El proceso de integración en el Espacio Europeo de Educación Superior: Necesidades y demandas del profesorado de la Universidad de Sevilla. Secretariado de Publicaciones, Universidad de Sevilla.

De Pablos, J. (Coord.) (2006b). Estudio prospectivo sobre las potencialidades de la Universidad de Sevilla para facilitar su adaptación al Espacio Europeo de Educación Superior (Documento inédito).

De Miguel, M. (Coord.) (2006). Metodologías de enseñanza y aprendizaje para el desarrollo de competencias. Orientaciones para el profesorado universitario ante el espacio europeo de educación superior. Madrid: Alianza Editorial.

Martínez Mut, B. y Otros (2005). El cambio de cultura docente en la universidad ante el Espacio Europeo de Educación Superior. SITE 2005. Instituto de Ciencias de la Educación, Universidad Politécnica de Valencia. [en línea] Disponible en: http://www.ice.upv.es/ site05/Ponencia2.pdf [consulta 2006, 7 de octubre]

Michavila, F. (Coord.) (2004). Las innovaciones educativas basadas en las tecnologías de la información en la formación universitaria presencial y a distancia. Dirección general de universidades. Ministerio de Educación y Ciencia.

Michavila, F. (2005). Cinco ideas innovadoras para la europeización de la educación superior. Revista de Universidad y Sociedad del Conocimiento, Vol. 2 (1). [en línea] Disponible en: http://www. uoc.edu/rusc/dt/esp/michavila0405. pdf [consulta 2006, 7 de octubre]

Molinuevo, J. L. (2004). Humanismo y nuevas tecnologías. Madrid: Alianza Editorial.

Molinuevo, J. L. (2006). La vida en tiempo real. La crisis de las utopías digitales. Madrid: Biblioteca Nueva.

O'Reilly, T. (2006). Qué es web 2.o. Patrones del diseño y modelos del negocio para la siguiente generación del software. [en línea] Disponible en: http:// sociedaddelainformacion.telefonica. es/jsp/articulos/detalle.jsp?elem $=2146$ [consulta 2006, 7 de octubre]

Pittinsky, M.(Comp.) (2006). La Universidad conectada. Perspectivas del impacto de Internet en la educación superior. Málaga: Ediciones Aljibe.

Postman, N. (2006) Cuestionamiento de los medios de comunicación, en Pittinsky, M.: La Universidad conectada. Perspectivas del impacto de Internet en la educación superior. Málaga: Ediciones Aljibe, 143-155.

Sancho, J. M. (1998). La tecnología: un modo de transformar el mundo cargado de ambivalencia, en Sancho, J. M.: Para una tecnología educativa. Barcelona: Horsori Editorial, 13-38.

Sancho, J. M. (2006). De tecnologías de la información y la comunicación a recursos educativos, en Sancho, J. M.: Tecnologías para transformar la educación. Madrid: UNIA/Akal, 15-49.

Shallis, M. (1984). El ídolo de silicio. Barcelona: Salvat. 


\section{PERFIL ACADÉMICO Y PROFESIONAL DEL AUTOR}

Juan de Pablos Pons es Catedrático de Universidad en el área de conocimiento Didáctica y Organización Escolar. Ha participado en diferentes publicaciones colectivas relativas a las aplicaciones educativas de las nuevas tecnologías de la información. Ha publicado trabajos de investigación en las principales revistas educativas españolas. Es el creador y director del Grupo de Investigación, Evaluación y Tecnología Educativa, adscrito a la Universidad de Sevilla y perteneciente al Plan Andaluz de Investigación.

E-mail: jpablos@us.es

DIRECCIÓN DEL AUTOR

Facultad de Ciencias de la Educación.

Universidad de Sevilla.

c/Camilo José Cela, s/n. Sevilla (41018)

Fecha de recepción del artículo: 11/06/07

Fecha de aceptación del artículo: 17/09/07 